Joseph Ifeanyichukwu Ikechebelu ${ }^{1-3}$, George Uchenna Eleje ${ }^{1,2 \star}$, Chidimma Donatus Okafor ${ }^{3}$ and Abdulhakeem Olajide Akintobi ${ }^{4}$

${ }^{1}$ Department of Obstetrics and Gynecology, Nnamdi Azikiwe University Teaching Hospital, PMB 5025,

Nnewi, Nigeria

${ }^{2}$ Effective Care Research Unit, Nnamdi Azikiwe

University, Nnewi Campus, Nigeria

${ }^{3}$ Life Institute for Endoscopy Division of Life

Specialist Hospital, Limited, Nnewi, Nigeria

${ }^{4}$ Department of Obstetrics \& Gynecology, Asokoro

District Hospital, FCT, Abuja, Nigeria

Dates: Received: 22 July, 2015; Accepted: 05 August, 2015; Published: 07 August, 2015

*Corresponding author: Dr. George Uchenna Eleje, Department of Obstetrics and Gynaecology, Nnamdi Azikiwe University Teaching Hospital, P.M.B. 5025, Nnewi, Anambra State, Nigeria, Tel: +2348068117444; E-mail: georgel21@yahoo.com www.peertechz.com

Keywords: Endometriosis; Infertility; Adhesion; Chocolate cyst

\section{Research Article \\ Endometriosis Seen at Diagnostic Laparoscopy for Women with Infertility}

\section{Introduction}

Endometriosis is usually defined as the presence of endometriallike tissue, that is, glands and stroma, outside the uterus [1]. It has remained a common and important health problem of women especially of the reproductive age.

The prevalence is estimated to be $8-10 \%$ in women of reproductive age [2], and increases to $30-40 \%$ among infertile women [3-5], although the precise rate in the general population is unknown because the pelvis has to be inspected at surgery (laparoscopy preferably) to make a definitive diagnosis [6]. The prevalence has been shown to vary with the laparoscopic method used.

The current view is that endometriosis rarely affects women of African descent. It is likely that the true prevalence is under reported [5]. While some reports have shown no significant difference in women of different races [7], others have shown lower prevalence in black women than in their Caucasian counterparts $[8,9]$.

Its aetiology has remained unknown. However, factors such as retrograde menstruation, heredity, impaired immune function and environmental toxins have been implicated [3]. A number of risk factors have been suggested in the aetiology of endometriosis. Although it has been known over many decades, the disease has been erroneously perceived to affect women of higher social class, probably because these women have more resources to seek medical attention [5].

The diagnosis of endometriosis is often strongly suspected from a patient's initial history. Infertility, dysmenorrhoea and dyspareunia are the main presenting complaints [10,11]. It is the most common cause of pelvic pain [5]. However, making a diagnosis on the basis of history alone is difficult as the presentation is so variable and other conditions may mimic the disease [12]. Laparoscopy is the gold standard for diagnostic purposes unless the disease is visible in the vagina or elsewhere $[1,6]$. However, non-invasive diagnostic methods such as transvaginal ultrasound and magnetic resonant imaging may also be complementary [3].

The disease can involve several sites in the body. The most common site of the disease is the ovary in approximately $50 \%$ of cases [3]. This is followed by the uterine cul-de-sac, posterior broad ligament, uterosacral ligaments, uterus, fallopian tubes, sigmoid colon, appendix, and round ligaments [3]. Implants may occur over the bowel, bladder, and ureters ${ }^{3}$. When endometriosis is present on the ovary, cysts may enlarge and are called 'endometriomas' or 'chocolate cysts' [3].

In the South-east Nigeria, until now, there have been uncertainties in making diagnosis of endometriosis. However, the innovation of laparoscopy in this region of the country has made a difference. This 
aim of the study is to determine the prevalence and laparoscopic features of endometriosis in women investigated for infertility using laparoscopy and dye test in Nnewi South-east Nigeria.

\section{Methods}

This is a retrospective survey at Life Institute for Endoscopy, Limited, Nnewi, Nigeria-a private specialist hospital, over a threeyear period between January 2006 and December 2008. This hospital, which has up to fifty bed capacity, offers varied services including laparoscopic surgery and assisted reproduction. Attendance to the hospital is via self-referral, and referral from both public and private hospitals. Data was collected with a pre-designed proforma. The data obtained included the age, literacy level, occupation of the husband, parity, and laparoscopic findings in various abdomino-pelvic organs involved among infertile women that underwent laparoscopy and dye test. Laparoscopy was done at both phases of the menstrual cycle, excluding menstrual period. The single puncture technique was used with diazepam injection $10 \mathrm{mg}$ and ketamine hydrochloride in a dosage between $50 \mathrm{mg}$ and $150 \mathrm{mg}$ given intravenously. Carbon dioxide was used to create pneumoperitoneum in all patients. All the patients gave an informed consent. Permission to conduct this study was sought for and granted by the hospital ethical committee. Only the data of patients with laparoscopic diagnosis of endometriosis were included in the study. Patients with prior histories of pelvic surgery and chronic pelvic inflammatory disease were excluded from the study. A total of 24 patients met the inclusion criteria. The social class was derived from the Olusanya, Okpere, Ezimokhai protocol of social classification [13]. The information extracted was analyzed using SPSS software version 16 (SPSS for windows, Version 16.0 Chicago: SPSS Inc.). The results were put in frequency tables and percentage.

\section{Results}

During the 3-year study period, 24 cases of endometriosis were diagnosed out of the 490 infertile women seen. This gave the prevalence of $4.9 \%$. The age distribution of the patients is shown in Table 1 . The mean age of the women was $30.3 \pm 4.1$ years. Majority 14 $(58.3 \%)$ of the patients were of social class I, followed by social class II $(4,16.7 \%)$, III $(3,12.5 \%))$, V (2, 8.3\%)) and IV (1, 4.2\%). Sixteen $(66.7 \%)$ of the patients presented with primary infertility, while 8 (33.3\%) had secondary infertility and were all primiparous.

Table 2 shows the Laparoscopic and Dye Test findings of the various abdomino-pelvic organs. The ovary is the commonest site involved. Sixteen $(33.3 \%)$ patients had involvement of bowel to adhesion.

\begin{tabular}{|l|c|c|}
\hline \multicolumn{2}{|l|}{ Table 1: The Age distribution of Patients } \\
\begin{tabular}{|l|c|c|}
\hline Age Range & Frequency & Percentage \\
\hline $21-25$ & 4 & 16.6 \\
\hline $26-30$ & 6 & 25.0 \\
\hline $31-35$ & 13 & 54.2 \\
\hline $36-40$ & 1 & 4.2 \\
\hline Total & 24 & 100.0 \\
\hline
\end{tabular}
\end{tabular}

Table 2: The Laparoscopic and Dye Test Findings of the Abdomino-pelvic Organs.

\begin{tabular}{|c|c|c|}
\hline FINDINGS & FREQUENCY & PERCENTAGE \\
\hline \multicolumn{3}{|l|}{ (1)OVARIAN } \\
\hline Bilateral Chocolate Cyst & 9 & 37.5 \\
\hline Unilateral Chocolate Cyst & 6 & 25.0 \\
\hline Normal ovaries & 7 & 29.2 \\
\hline Ovaries not visualized & 2 & 8.3 \\
\hline TOTAL & 24 & 100 \\
\hline \multicolumn{3}{|l|}{ (2) TUBAL } \\
\hline Bilateral Tubal Adhesion & 13 & 54.2 \\
\hline Unilateral Tubal Adhesion & 5 & 20.8 \\
\hline Normal Tubes & 2 & 8.3 \\
\hline Tubes not visualized & 4 & 16.7 \\
\hline TOTAL & 24 & 100 \\
\hline \multicolumn{3}{|l|}{ (3) DYE TEST } \\
\hline Bilateral Tubal Blockade & 8 & 33.3 \\
\hline Unilateral Tubal Blockade & 3 & 12.5 \\
\hline Bilateral Patent Tubes & 13 & 54.2 \\
\hline TOTAL & 24 & 100.0 \\
\hline \multicolumn{3}{|l|}{ (4) CUL-DE-SAC } \\
\hline Covered by Adhesion & 17 & 65.4 \\
\hline Occupied by Chocolate Cyst & 6 & 23.1 \\
\hline Occupied by Fibroid & 2 & 7.7 \\
\hline Normal & 1 & 3.8 \\
\hline TOTAL & *26 & 100.0 \\
\hline \multicolumn{3}{|l|}{ (5) BOWEL } \\
\hline Adhesion & 8 & 33.3 \\
\hline Normal & 16 & 66.7 \\
\hline TOTAL & 24 & 100.0 \\
\hline
\end{tabular}

\section{Discussion}

As seen in this study, the laparoscopic findings of endometriosis have become very relevant in infertility management. Thus, laparoscopy has become the most important investigative tool for the evaluation of endometriosis and tubal disease in developed countries of the world [6]. Endometriosis is considered one of the three major causes of female infertility. In mild to moderate cases, the infertility may be just temporary. In these cases, surgery to remove adhesions, cysts, and scar tissue can restore fertility. In other cases (a very small percentage), women may remain infertile. Physicians are still not clear how endometriosis affects fertility. Additionally, this study substantially argues against the perception that endometriosis is rare among women of African descent. The prevalence of $4.9 \%$ was akin to 4.7\% reported by Hebbar and Chawla [14] but much higher than the previous reports in Nigeria [15-17]. However, it was lower than 21\% reported in developed countries [18].

More recently, Fawole et al. [19], reported a prevalence of $48.1 \%$ for endometriosis among symptomatic women which remains the 
highest prevalence of endometriosis reported in Africa, the next highest figure being the $20 \%$ prevalence reported by Alabi et al. [20]. The deliberate search for endometriosis in these studies could be responsible for the reported high prevalence. Hence, it is expected that the prevalence of endometriosis in women of African descent is likely to increase in studies performed by gynaecologist who are trained in the use of laparoscopy for recognizing endometriosis [5].

Unlike in the study done in Nigeria by Ekwempu [21] where endometriosis is found mainly in lower social class, our study has revealed that the majority of patients were of social class I. This could be that more of the affluence couples in our society afford the laparoscopy. This result could also be accidental findings. Endometriosis however, cuts across every social class [7].

All the patients in this review were either nulliparous or primiparous. In a previous review paper, 20 cases were reported and $82 \%$ were nulliparous black women [22]. In our case, $66.6 \%$ of the patients were nulliparous.

In this study, 'endometriomas' or 'chocolate cysts' were seen in more than half of the patients. This finding is fully in agreement with documentations in the literature $[1,3]$. However, rupture of the chocolate cysts in the abdominal cavity, with the release of endometrial cells and blood could cause peritoneal irritation leading to ascites and this can worsen the infertility problems [5]. This then justifies appropriate and timely management of cases of ovarian endometriosis.

Despite the fact that almost all the patients have tubal adhesions at laparoscopy, more than $50 \%$ of them have bilateral patency of the tubes at dye test. This result also agrees with documentation in the literature. Tubal occlusion has been found to be rare in patients with endometriosis [3]. This may mean that other mechanisms are involved in the infertility experienced in patients with endometriosis [23].

Nevertheless, moderate and severe endometriosis is associated with pelvic adhesions that distort pelvic anatomy, prevent normal tubo-ovarian apposition and encase the ovary [3]. A systematic review suggests that pregnancies are halved in endometriosis in comparison with tubal infertility [24]. In advanced endometriosis, diminished ovarian reserve, poor oocyte and embryo quality and impaired implantation have also been suggested [25]. The peritoneal fluid from women with endometriosis containing high levels of cytokines, growth factors and activated macrophages have been shown to be toxic to sperm function and embryo survival [26].

The causes of endometriosis are still unknown, although many theories abound. Although, this could not be concluded from this present study, one theory suggests that during menstruation some of the tissue backs up through the fallopian tubes into the abdomen, a sort of "retrograde menstruation," where it attaches and grows. Another theory states that certain families may have predisposing genetic factors to the disease. Current research is also looking at the role of the immune system in activating cells that may secrete factors which stimulate endometriosis [6].

However, for many women, simply having a diagnosis of endometriosis brings relief. Diagnosis begins with a gynaecologist evaluating the medical history and a complete physical examination of the patients. A diagnosis of endometriosis can only be certain when the physician performs a laparoscopy. As was done in all patients in this study, using the laparoscope to see into the pelvic area can often be used to determine the locations, extent, and size of the endometrial growths. Although, other examinations which may be used in the diagnosis of endometriosis may not have been used in these patients analysed, biopsy samples could be removed often during a laparoscopy, for examination under a microscope to determine if cancer or other abnormal cells are present.

One major limitation of this study was our inability to do the pathologic confirmation (histological presence of endometrial glands and stroma) of the laparoscopic appearance. The comparison of clinical characteristic of infertile women with and without endometriosis, including other clinical characteristic like smoking and body mass index which are related with this disease would have benefited the study; but this was not evaluated. However, the few number of information about the real prevalence of endometriosis in women of African descent is strength of the study.

In conclusion, endometriosis is an important common gynaecological problem among infertile women and laparoscopy remains a valuable diagnostic tool. Chocolate cysts and cul-de-sac adhesion were seen in $62.5 \%$ and $65.4 \%$ of cases respectively while majority (54.2\%) had bilateral patent tubes. Efforts should be made to make laparoscopy available and affordable in gynaecological practice especially in developing country settings.

\section{Declaration of Interest}

The authors report no conflicts of interest. The authors alone are responsible for the contents and writing of the paper.

\section{References}

1. Kennedy S, Koninckx P (2007) Endometriosis. In: Edmonds DK (Ed). Dewhurst's Textbook of Obstetrics and Gynaecology. Seventh Edition; Blackwell Publishing Company. London 430-439.

2. Eskenazi B, Warner ML (1997) Epidemiology of Endometriosis. Obstet Gynaecol Clin North Am. 1997 24: 235-258.

3. Sarajari S, Muse KN, Decherney AH (2007) Endometriosis. In: Decherney AH, Nathan L, Goodwin TM, Laufer N (Eds). Current Diagnosis and Treatment in Obstetrics and Gynaecology. 10th Edition. McGrawHill Medical Publishing Division. New York 712-719.

4. Taylor RN, Lundeeni SG, Giudice LC (2002) Emerging Role of Genomics in Endometriosis Research. Fertil Steril 78: 694-698.

5. Kyama CM, Mwenda JM, Machoki J, Milhalyi A, Simsa P, et al. (2007) Endometriosis in African Women. Women's Health 3: 629-635.

6. Janssen EB, Rijkers AC, Hoppenbrouwers K, Meuleman C, D'Hooghe TM (2013) Prevalence of endometriosis diagnosed by laparoscopy in adolescents with dysmenorrhea or chronic pelvic pain: a systematic review. Hum Reprod Update 19: 570-582.

7. Mangtani P, Booth M (1993) Epidemiology of Endometriosis. J. Epidemiol. Community Health 47: 84-88.

8. Arumugam K, Templeton AA (1994) Endometriosis and Race. Aust NZJ Obstet Gynaecol 32: 164-165.

9. Miyazawa K (1976) Incidence of Endometriosis among Japanese Women Obstet Gynaecol 48: 408-409. 
10. Porpora MG, Koninckx PR, Piazze J, Natili M, Colagrande S, et al. (1999) Correlation between endometriosis and Pelvic Pain. J Am Assoc Gynaeco Laparosc 6: 429-434.

11. Vlahos N, Fortner KB (2005) Emerging Issues in Endometriosis. Post Obstet Gynaecol 25: 1-9.

12. Montalto M, Santoro L, D'Onofrio F, Gallo A, Campo S, Campo V, et al. (2010) Endometriosis, need for a multidisciplinary clinical setting: the internist's point of view. Intern Emerg Med 5: 463-467.

13. Olusanya O, Okpere EE, Ezimokhai M (1985) The importance of social class in voluntary fertility control in a developing country. West Afr J Med 4: 205 212

14. Hebbar S, Chawla C (2005) Role of laparoscopy in evaluation of chronic pelvic pain. J Minim Access Surg 1: 116-120.

15. Otubu JAM (2009) Tubal Infertility. Lecture delivered at Revision/Update Course of the WACS in Obstetrics and Gynaecology at National Hospital Abuja; March 16-21, 2009.

16. Otolorin EO, Ojengbede O, Falase AO (1987) Laparoscopic Evaluation of Tuboperitoneal Factor in Infertile Nigerian Women. Int, J. Gynaecol Obstet 25: 47-52.

17. Tharcher CD, Nwana EJC, Karshima JA (1997) Extrapelvic Endometriosis in Nigeria. Int J Gynaecol Obstet 57: 57-58.
18. Sule JO, Erigbali P, Eruom L (2008) Prevalence of Infertility in Women in a Southwestern Nigerian Community. African Journal of Biomedical Research 11: $225-227$

19. Fawole AO, Bello FA, Ogunbode O, Odukogbe AT, Nkwocha GC, et al (2015) Endometriosis and associated symptoms among Nigerian women. Int J Gynaecol Obstet 130: 190-194.

20. Alabi OC, Zowa PK, Onwumere UM (2013) Incidence of endometriosis on laparoscopy in a Nigerian Hospital. Trop J Obstet Gynaecol 30: S28.

21. Mahmood TA, Templeton A (1991) Prevalence and Genesis of Endometriosis. Hum Reprod 6: 544-549.

22. Ekwempu CC, Harrison KA (1979) Endometriosis among the Hausa/ Fulani Population of Nigeria. Trop Geogr Med 3: 201-205.

23. Spitzer M, Benjamin F (1995) Ascites due to Endometriosis. Obstet. Gynaeco Surv 50: 628-631.

24. Barhart KT, Dunsmoor SR, Coutifaris C (2002) Effects of Endometriosis on in vitro Fertilization. Fertil Steril 77: 1148-1155.

25. Brosens I (2004) Endometriosis and Outcome of in-vitro Fertilization. Ferti Steril 81: 1198-2000

26. Guidice LC, Kao LC (2004) Endometriosis. Lancet 364: 1890-799.

Copyright: (c) 2015 Ikechebelu Jl, et al. This is an open-access article distributed under the terms of the Creative Commons Attribution License, which permits unrestricted use, distribution, and reproduction in any medium, provided the original author and source are credited. 